\title{
Quantifying burden of disease to support public health policy in Belgium: opportunities and constraints
}

\author{
Brecht Devleesschauwer ${ }^{1,2^{*}}$, Charline Maertens de Noordhout ${ }^{1}$, G Suzanne A Smit ${ }^{2}$, Luc Duchateau ${ }^{3}$, Pierre Dorny ${ }^{2,4}$, \\ Claudia Stein ${ }^{5}$, Herman Van Oyen ${ }^{6}$ and Niko Speybroeck
}

\begin{abstract}
Background: To support public health policy, information on the burden of disease is essential. In recent years, the Disability-Adjusted Life Year (DALY) has emerged as the most important summary measure of public health. DALYs quantify the number of healthy life years lost due to morbidity and mortality, and thereby facilitate the comparison of the relative impact of diseases and risk factors and the monitoring of public health over time.

Discussion: Evidence on the disease burden in Belgium, expressed as DALYS, is available from international and national efforts. Non-communicable diseases and injuries dominate the overall disease burden, while dietary risks, tobacco smoking, and high body-mass index are the major risk factors for ill health. Notwithstanding these efforts, if DALYs were to be used for guiding health policy, a more systematic approach is required. By integrating DALYs in the current data generating systems, comparable estimates, rooted in recent local data, can be produced. This might however be hampered by several restrictions, such as limited harmonization, timeliness, inclusiveness and accessibility of current databases.
\end{abstract}

Summary: Routine quantification of disease burden in terms of DALYS would provide a significant added value to evidence-based public health policy in Belgium, although some hurdles need to be cleared.

Keywords: Belgium, Disease burden, Disability-adjusted life years, Health policy

\section{Background}

The main goal of public health policy is to promote, enhance and protect the population's health. This requires information on the health status of the population, often referred to as the "burden of disease". More than just the presence/absence of specific diseases and conditions, disease burden encompasses a comprehensive quantification of the physical and psychosocial health impact of diseases, conditions, and risk factors [1].

Evidence on the disease burden is important for decisionmaking processes within the health sector. In order to make relevant decisions and set appropriate priorities, policy makers need to be informed about the size of health

\footnotetext{
* Correspondence: brecht.devleesschauwer@UGent.be

'Institute of Health and Society (IRSS), Faculty of Public Health, Université catholique de Louvain, Brussels, Belgium

${ }^{2}$ Department of Virology, Parasitology and Immunology, Faculty of Veterinary Medicine, Ghent University, Salisburylaan 133, 9820 Merelbeke, Belgium

Full list of author information is available at the end of the article
}

problems in the population, the groups that are particularly at risk, and the trends in the state of health over time. In addition, an accurate estimate of the population's health status can be used for determining the expected health care use and is vital for prioritizing effective interventions and evaluating their impact and cost-effectiveness (e.g., by integrating them in generalized cost-effectiveness analyses [2]).

The disease burden of the population can be described by a variety of indicators. Indeed, public health is a multifactorial phenomenon with many facets and different ways to measure it. Typical indicators of population health are life expectancy, cause-specific mortality rates, numbers of new and existing cases of specific diseases (i.e., incidence and prevalence), perceived health, the occurrence of physical and mental limitations and disability, but also more indirect measures, such as absenteeism, incapacity of work, and the use of medical facilities and the associated 
costs. However, all these indicators highlight only one facet of public health, i.e., either mortality or morbidity.

Summarizing public health in terms of mortality-based indicators, such as life expectancy, dates from the time when only reliable data for mortality existed. In many countries, however, one has been confronted with an epidemiological transition of public health problems. The importance of early mortality due to plagues and famines has been replaced by chronic, non-communicable diseases, while communicable diseases remain a real threat, causing a "double burden" [3]. Cardiovascular diseases and cancers have replaced infectious diseases as the main causes of death. However, these diseases are also associated with an important morbidity component, due to the life prolonging effect of continuously improving medical practice [4]. Moreover, not only an extended life expectancy per se is aimed for, living these extra years in good health has become just as important [5]. As a result, current health policy requires a global overview of public health, one that combines morbidity and mortality and takes account of health-related quality of life (HRQoL; [6]).

Given the importance of combining morbidity and mortality, the last few decades have seen important methodological advances in so-called summary measures of population health (SMPH; [7]). By and large, SMPHs may be divided into two broad families, namely health expectancies and health gaps. Metrics of each family combine morbidity and mortality into a single figure. Health expectancy-based metrics, such as Disability-Free Life Expectancy (DFLE), Healthy Life Years (HLY), and Disability-Adjusted Life Expectancy (DALE), translate these indicators into a health-adjusted life expectancy; health gap metrics, such as the Disability-Adjusted Life Year (DALY), translate these indicators into a number of life years lost due to bad health and mortality.

Driven by the influential Global Burden of Disease (GBD) projects initiated in the early 1990s, the DALY has become the dominant SMPH [8-12]. In the remainder of this debate, we will therefore outline the composition of the DALY metric and its data needs. Next, we will summarize existing DALY estimates for Belgium, providing an overview of the current state-of-knowledge on the burden of disease in Belgium. We will conclude by discussing the added value and potential hurdles of routine DALY calculation for Belgian public health policy.

\section{Discussion}

\section{Disability-adjusted life years What are DALYs?}

The DALY concept was developed for the World Bank's World Health Report 1993, Investing in Health [13]. To estimate the global burden of disease, the World Bank required a metric that allowed comparing health across countries. Equity issues were therefore central concepts in the development of DALYs $[14,15]$.

DALYs measure the health gap from a life lived in perfect health, and quantify this health gap as the number of potentially healthy life years lost due to morbidity, disability and mortality. A disease burden of 100 DALYs per 1000 people-year would thus imply a loss of 100 healthy life years per 1000 people per year. Diseases or risk factors accounting for more DALYs thus have a higher public health impact.

The DALY is composed of a morbidity and a mortality component [14-16]. Morbidity is quantified in terms of Years Lived with Disability (YLDs), the loss of healthy life years from living in a less-than-perfect health state. YLDs for a given health state are calculated by multiplying the number of incident cases with the duration and the disability weight of the health state. An alternative, prevalence-based version of the YLD, introduced in the GDB 2010 study, is defined as the number of prevalent cases multiplied with the disability weight [1]. In both versions, the disability weight is a crucial component, reflecting the relative reduction in HRQoL on a scale from zero (perfect health) to one (worst possible health state). Mortality is quantified in terms of Years of Life Lost (YLLs), the loss of healthy life years from dying before a predefined life expectancy. YLLs are calculated by multiplying the number of deaths with the residual life expectancy at the age of death. The standard DALY formulas may be extended by applying age weighting or time discounting [14-16]. These so-called social weighting functions are however not accepted by all authors $[17,18]$. As a result, the use of age weighting and time discounting is declining, even in the most recent updates of the GBD $[1,12]$.

\section{Data needs}

It is obvious that the quality of the DALY estimate directly depends on the quality of the input data [19]. To obtain the most accurate DALY estimate, it is therefore necessary to have reliable incidence (or prevalence) and mortality data. Ideally, one would like to have data from a nationally representative system that continuously monitors the occurrence of all disorders in the population, based on a set of clearly defined diagnostic criteria. As such registration does not exist, one must resort to what exists. In Belgium, several large and important data generating systems are in place:

- The national health surveys (performed in 1997, 2001, 2004, 2008 and 2013; https://his.wiv-isp.be/)

- The national cancer registry (http://www. kankerregister.org/)

- The 40 national reference centers and 16 national reference laboratories for human microbiology (https://nrchm.wiv-isp.be/; [20]) 
- The network of sentinel GPs and sentinel microbiology laboratories (https://www.wiv-isp. be/epidemio/epien/index8.htm; [21])

- The mandatory reporting of specific agents.

Taking into account the level of under-reporting and under-ascertainment, these data sources can provide valuable information on the incidences of the included diseases and risk factors.

The direct use of healthcare providers' data is difficult in Belgium, given the stringent privacy rules in place [22]. However, certain data are made available as Minimal Clinical, Hospital, Nursing, and Psychiatric Data. These data sources are merely focused on the financial impact of diseases, and thus provide valuable information for estimating the direct health-related costs [23]. The announced intention to update the disease classification system to ICD-10-BE (International Classification of Disease, $10^{\text {th }}$ Revision - Belgian Modification) in the domain Medical Data of the Minimal Hospital Data [24], might prove valuable for health impact assessment studies, given that non-aggregated data are made available.

In addition to the national data collection systems, there are various data collection mechanisms at the regional level. However, the routine use of these data sources to generate nationally relevant burden estimates might be problematic, due to the lack of harmonization between databases and data collection procedures in the different Belgian regions. Moreover, the diseases that are being registered are different between regions, making the availability of the routine data incomplete for a part of the country.

When local data are not readily available, one may resort to international databases or data from neighboring countries. However, Vanthomme et al. [25] report that lack of timeliness can be an important constraint to the use of three major health databases (i.e., WHO-HFA, OECD, and EUROSTAT). Also, when extrapolating data from neighboring countries, one assumes that the Belgian health situation is similar to that of its neighbors.

The lack of data harmonization in the Belgian system is mainly because of the absence of a unique national system of health data collection. There are several individual initiatives from public and private institutions, but communication between these different actors is poor. Several registries for the same disease exist (e.g. diabetes registry), but the stage from which the patient is included into a certain registry is sometimes poorly defined. Moreover, the codes used to define the disease, the identification of the patients and the follow-up period are different between registries making them impossible to merge. The split of health competences between federal state, regions and communities is one of the explanations of this disparate system of health data collection.
Finally, several diseases are not well registered in Belgium, such as foodborne diseases (FBD) and especially diseases caused by chemicals. The impact of FBD on public health is difficult to evaluate and these diseases are not prioritized in Belgium, creating a vicious circle of lacking data [26].

\section{The burden of disease in Belgium}

Estimates on the burden of disease in Belgium are available from both international and national efforts. However, if disease burden were to support policy, a more systematic approach is required, generating comparable estimates rooted in recent, local data.

\section{International efforts}

To date, the two most comprehensive sources of disease burden estimates for Belgium are the most recent GBD studies conducted by the World Health Organization (WHO) and the Institute for Health Metrics and Evaluation (IHME). The results of WHO's so-called Global Health Estimates (GHE) are available online as a series of spread sheet documents (http://www.who.int/healthinfo/global_ burden_disease/estimates/en/index2.html). The results of IHME's GBD 2010 study are available online via interactive data visualization tools (http://www.healthdata.org/ gbd/data-visualizations), via detailed databases [27] and via a summary report $[28,29]$.

According to WHO GHE, the total disease burden in Belgium in 2012 was 29.468 DALYs per 100,000, of which $41 \%$ was due to morbidity and $59 \%$ due to mortality. Noncommunicable diseases attributed $85 \%$, injuries $10 \%$, and the group of communicable, maternal, perinatal and nutritional conditions the remaining 5\%. The group of non-communicable diseases was dominated by malignant neoplasms and cardiovascular diseases (each contributing $\sim 20 \%$ ), followed by mental, neurological and musculoskeletal disorders (each contributing 10\%). Falls, road traffic accidents and self-harm were each responsible for $20-30 \%$ of the entire injury burden. Lower respiratory infections dominated the communicable disease burden (37\% of communicable, maternal, perinatal and nutritional conditions). Table 1 shows the top 20 causes of DALYs, YLDs and YLLs for Belgium in 2012 according to WHO, and their change in ranking since 2000. There has been a significant increase in the importance of Alzheimer's disease and falls, while the relative importance of road traffic accidents and breast cancer has decreased.

The GBD 2010 study showed a broadly similar picture $[28,29]$, which is not surprising as WHO GHE adopted most GBD 2010 YLD estimates and used the same mortality data for calculating YLLs. Nevertheless, there are slight differences in methods, data sources and groupings of causes [12]. Table 2 shows the top 20 causes of DALYs, YLDs and YLLs for Belgium in 2010 according to IHME, 
Table 1 Top 20 causes of Disability-Adjusted Life Years (DALY), Years Lived with Disability (YLD) and Years of Life Lost (YLL) in Belgium, 2012, according to WHO global health estimates

\begin{tabular}{|c|c|c|c|c|c|c|}
\hline Rank & DALY & & YLD & & YLL & \\
\hline 1 & Ischaemic heart disease & {$[=]$} & Back and neck pain & {$[=]$} & Ischaemic heart disease & {$[=]$} \\
\hline 2 & Other circulatory diseases & {$[=]$} & Unipolar depressive disorders & {$[=]$} & Trachea, bronchus, lung cancers & {$[=]$} \\
\hline 3 & Trachea, bronchus, lung cancers & {$[=]$} & Falls & {$[=]$} & Other circulatory diseases & {$[=]$} \\
\hline 4 & Back and neck pain & {$[+1]$} & Other musculoskeletal disorders & {$[=]$} & Stroke & {$[=]$} \\
\hline 5 & $\begin{array}{l}\text { Alzheimer's disease and other } \\
\text { dementias }\end{array}$ & {$[+6]$} & Alcohol use disorders & {$[=]$} & Other malignant neoplasms & {$[+1]$} \\
\hline 6 & Chronic obstructive pulmonary disease & {$[=]$} & $\begin{array}{l}\text { Alzheimer's disease and other } \\
\text { dementias }\end{array}$ & {$[=]$} & Chronic obstructive pulmonary disease & {$[+1]$} \\
\hline 7 & Unipolar depressive disorders & {$[=]$} & Chronic obstructive pulmonary disease & {$[=]$} & $\begin{array}{l}\text { Alzheimer's disease and other } \\
\text { dementias }\end{array}$ & {$[+6]$} \\
\hline 8 & Stroke & {$[-4]$} & Ischaemic heart disease & {$[=]$} & Self-harm & {$[-3]$} \\
\hline 9 & Falls & {$[+3]$} & Anxiety disorders & {$[=]$} & Colon and rectum cancers & {$[=]$} \\
\hline 10 & Other malignant neoplasms & {$[-1]$} & Migraine & {$[=]$} & Lower respiratory infections & {$[+1]$} \\
\hline 11 & Alcohol use disorders & {$[+2]$} & Osteoarthritis & {$[=]$} & Breast cancer & {$[-1]$} \\
\hline 12 & Self-harm & {$[-2]$} & Road injury & {$[=]$} & Other digestive diseases & {$[=]$} \\
\hline 13 & Other musculoskeletal disorders & {$[+2]$} & Asthma & {$[=]$} & Road injury & {$[-5]$} \\
\hline 14 & Colon and rectum cancers & {$[+2]$} & Schizophrenia & {$[=]$} & Cirrhosis of the liver & {$[=]$} \\
\hline 15 & Road injury & {$[-7]$} & Other circulatory diseases & {$[+1]$} & Other unintentional injuries & {$[+4]$} \\
\hline 16 & Other digestive diseases & {$[+2]$} & Drug use disorders & {$[-1]$} & Pancreas cancer & {$[+1]$} \\
\hline 17 & Breast cancer & {$[-3]$} & Bipolar disorder & {$[=]$} & Other respiratory diseases & {$[-2]$} \\
\hline 18 & Lower respiratory infections & {$[-1]$} & Other unintentional injuries & {$[=]$} & Other infectious diseases & {$[+2]$} \\
\hline 19 & Other unintentional injuries & {$[+1]$} & Rheumatoid arthritis & {$[=]$} & Lymphomas, multiple myeloma & {$[-1]$} \\
\hline 20 & Anxiety disorders & {$[+2]$} & Stroke & {$[=]$} & Falls & {$[+3]$} \\
\hline
\end{tabular}

The change in rank since 2000 is given between brackets, with ' + ' indicating an increase in rank, ' - ' a decrease in rank, and ' $=$ ' a status quo.

and their change in ranking since 1990. In this 20-year period, the most striking increases are again those of the neurological, mental and musculoskeletal disorders.

GBD 2010 further provides estimates on the contribution of risk factors to the disease burden. In the general population, the three most important risk factors were dietary risks (e.g., high sodium, low fruits and vegetables), tobacco smoking, and high body-mass index. Second-hand smoke exposure was a leading risk factor for children under 5 , while alcohol use was the major risk factor for adults aged 15-49.

In addition to these global consortia, the European Centre for Disease Control (ECDC) is currently undertaking a burden of communicable disease study in Europe [30]. In a pilot study, the burden of six infectious diseases was quantified, though only YLDs could be calculated (Figure 1; [31]).

\section{National efforts}

So far, only few national efforts have been undertaken to study the disease burden in Belgium. The DALY as policy-relevant measure for Belgium was first described by Baert et al. [32], in the Flemish Health Indicator
Report 1998. To demonstrate the use of DALYs, the authors initiated a pilot study in which they quantified the Flemish disease burden for reference year 1997 [33]. The list of included diseases and risk factors was inspired by the Dutch national disease burden study [34]. DALYs were calculated based on the Flemish life expectancy table, using non-uniform age weighting and a $3 \%$ time discount rate, making these estimates incomparable with the aforementioned GBD estimates.

More recently, the Flemish Institute for Technology and Development (VITO) assessed the burden of environmental risk factors in Flanders, commissioned by the Flemish Environment Agency (VMM; [35]). Figure 2 summarizes their findings, showing air particulate matter to be the most important environmental risk factor.

In addition to these larger studies, several researchers estimated the burden of specific health conditions in Belgium. However, as DALY calculation methods differed across studies, care should be taken in comparing the resulting estimates. Stassen et al. [36] estimated the mean burden due to transportation noise in Flanders in 2004 to be 20,517 DALYs, or 342 DALYs per 100,000. Dhondt et al. [37] quantified the burden of road traffic accidents in 
Table 2 Top 20 causes of Disability-Adjusted Life Years (DALY), Years Lived with Disability (YLD) and Years of Life Lost (YLL) in Belgium, 2010, according to IHME GBD 2010

\begin{tabular}{|c|c|c|c|c|c|c|}
\hline Rank & DALY & & YLD & & YLL & \\
\hline 1 & Ischaemic heart disease & {$[=]$} & Low back pain & {$[=]$} & Ischaemic heart disease & {$[=]$} \\
\hline 2 & Low back pain & {$[=]$} & Major depressive disorder & {$[=]$} & Lung cancer & {$[+1]$} \\
\hline 3 & Stroke & {$[=]$} & Falls & {$[+2]$} & Stroke & {$[-1]$} \\
\hline 4 & Lung cancer & {$[=]$} & Neck pain & {$[-1]$} & Self-harm & {$[+1]$} \\
\hline 5 & COPD & {$[=]$} & Other musculoskeletal & {$[-1]$} & COPD & {$[+1]$} \\
\hline 6 & Falls & {$[+3]$} & COPD & {$[=]$} & Colorectal cancer & {$[+1]$} \\
\hline 7 & Major depressive disorder & {$[=]$} & Alzheimer's disease & {$[+5]$} & Road injury & {$[-3]$} \\
\hline 8 & Alzheimer's disease & {$[+8]$} & Diabetes & {$[+2]$} & Lower respiratory infections & {$[+2]$} \\
\hline 9 & Self-harm & {$[-1]$} & Ischaemic heart disease & {$[=]$} & Breast cancer & {$[-1]$} \\
\hline 10 & Road injury & {$[-4]$} & Migraine & {$[-2]$} & Alzheimer's disease & {$[+6]$} \\
\hline 11 & Neck pain & {$[-1]$} & Anxiety disorders & {$[-4]$} & Other cardio \& circulatory & {$[-2]$} \\
\hline 12 & Other musculoskeletal & {$[+2]$} & Drug use disorders & {$[-1]$} & Cirrhosis & {$[-1]$} \\
\hline 13 & Diabetes & {$[-2]$} & Osteoarthritis & {$[+1]$} & Pancreatic cancer & {$[+4]$} \\
\hline 14 & Colorectal cancer & {$[-1]$} & Road injury & {$[-1]$} & Diabetes & {$[-1]$} \\
\hline 15 & Other cardio \& circulatory & {$[=]$} & Alcohol use disorders & {$[=]$} & Falls & {$[+5]$} \\
\hline 16 & Breast cancer & {$[-4]$} & Asthma & {$[+1]$} & Prostate cancer & {$[+3]$} \\
\hline 17 & Lower respiratory infections & {$[=]$} & Schizophrenia & {$[+2]$} & Brain cancer & {$[+1]$} \\
\hline 18 & Migraine & {$[+1]$} & Other hearing loss & {$[-2]$} & Leukaemia & {$[+3]$} \\
\hline 19 & Anxiety disorders & {$[+1]$} & Dysthymia & {$[+2]$} & Stomach cancer & {$[-7]$} \\
\hline 20 & Cirrhosis & {$[-2]$} & Bipolar disorder & {$[=]$} & Chronic kidney disease & {$[+2]$} \\
\hline
\end{tabular}

The change in rank since 1990 is given between brackets, with ' + ' indicating an increase in rank, ' - ' a decrease in rank, and ' $=$ ' a status quo.

Flanders and Brussels. They estimated a total of 182,379 DALYs, or 1030 DALYs per 100,000. In absolute numbers, car users contributed most DALYs, whereas per travelled $\mathrm{km}$, motorcyclists contributed most. Henrard et al. [38] estimated the burden of haemophilia in Belgium in 2011 at 145 DALYs (95\% credible interval [CI]: 90-222), or 1.3 DALYs per 100,000 (95\% CI: 0.8-2.0).

\section{Summary}

By quantifying the total disease burden and the contribution of different diseases and risk factors, DALYs are a highly valuable measure to set priorities for public health research and policy. Furthermore, if data allow, DALYs may be calculated for different socioeconomic groups or geographic regions, allowing for a more detailed perspective on public health. By regularly updating the DALY estimates based on the best available data, trends in public health may be monitored over time, and the impact of macro-level policies may be evaluated. As a result, DALYs may be important tools to support policy that aims to improve general population health and reduce health inequalities [39]. For this reason, the IHME is initiating

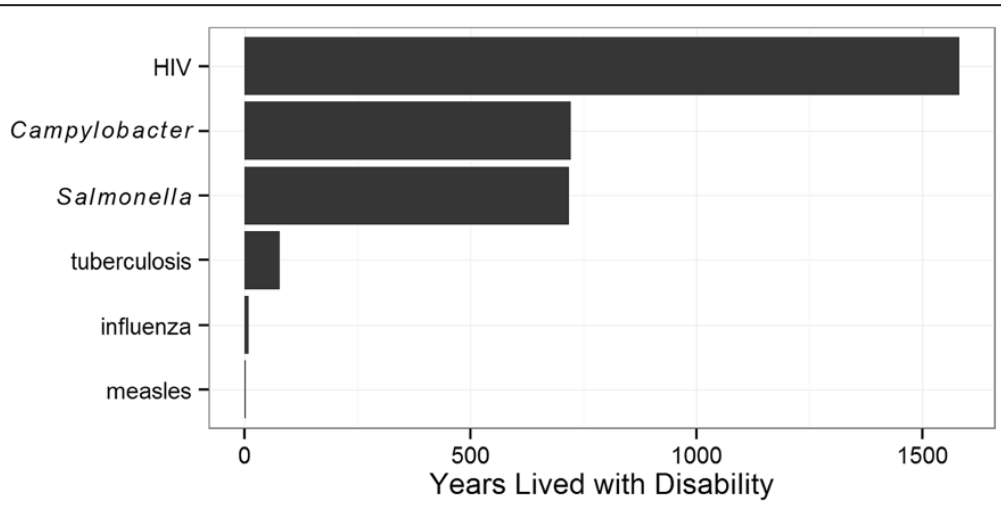

Figure 1 Years lived with disability calculated in a pilot study on communicable diseases in Europe, based on data from 2003 to 2005 [30,31]. 


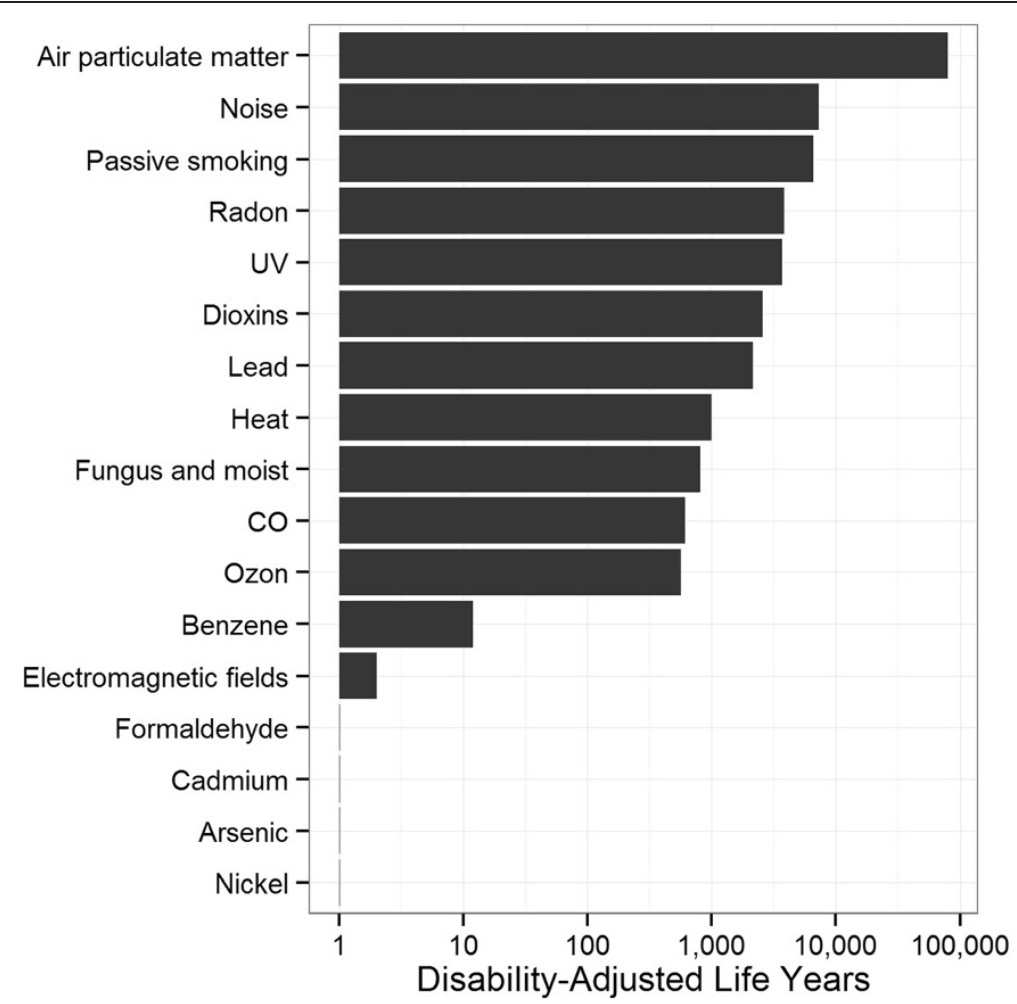

Figure 2 Disability-adjusted life years for environmental risk factors in Flanders, based on data from 1998 to 2011 [35]. Note that the $x$-axis uses a logarithmic scale.

national and subnational burden of disease studies, worldwide [40]. The WHO Regional Office for Europe is collaborating with IHME to facilitate national burden of disease study in the European region and enhance consistency of burden estimates.

Current DALY estimates for Belgium highlight the importance of non-communicable diseases and injuries. However, several constraints can be identified that might hamper the policy relevance of the currently available estimates. First, most DALY estimations remained academic exercises, with little or no direct knowledge transfer to the concerned policy instances. Indirect knowledge transfer may have occurred by referring to existing burden estimates in research proposals, but the effect is difficult to assess. Second, while global estimates provide a broad overview of the health status in Belgium, it remains a question to what extent these estimates are grounded in the best available local data. There may also be issues related to timeliness and ownership of these global estimates. Third, while national research groups did more efforts to apply local data sources, there appears to be little consistency in the applied DALY calculation methodology. As a result, the individual DALY studies cannot be combined to obtain a comparable evaluation of Belgians' health. Researchers are therefore advised to calculate
DALYs under different social weighting scenarios, and to present at least relative DALY estimates (e.g., DALYs per 100,000 people-year).

To overcome these limitations and generate a systematic and truly comparable measurement of Belgians' health, DALYs should be integrated in the different official data collection systems. This is already the case in the Netherlands and Australia, where DALYs are guiding health policy since the past 10-20 years [34,41]. In Belgium, various large and important data generation systems are in place that could provide the data required for calculating DALYs. However, there are also some potential hurdles, such as a lack of timeliness of certain databases, a restricted access to hospital data for routine use, a limited harmonization between regional databases, and the absence of certain diseases from the major databases. Given the increasing importance of neurological, mental and musculoskeletal disorders, the absence of comprehensive, harmonized databases for these disorders is particularly striking. Nevertheless, we believe that the routine quantification of disease burden in terms of DALYs would provide a significant added value to public health policy in Belgium and should be integrated in all national mechanisms for the translation of evidence into policy. 


\section{Abbreviations}

DALE: Disability-adjusted life expectancy; DALY: Disability-adjusted life year; DFLE: Disability-free life expectancy; DW: Disability weight; ECDC: European centre for disease control; FBD: Foodborne disease; GBD: Global burden of disease; HLY: Healthy life year; HRQoL: Health-related quality of life; IHME: Institute for Health Metrics and Evaluation; SMPH: Summary measure of public health; VITO: Flemish Institute for Technology and Development; VMM: Flemish Environment Agency; WHO: World Health Organization; YLD: Year lived with disability; YLL: Year of life lost.

\section{Competing interests}

The authors declare that they have no competing interests.

\section{Authors' contributions}

$B D, C M d N$ and GSAS compiled the data on the burden of disease in Belgium. BD wrote the first draft of the manuscript. All authors contributed to further versions of the manuscript and approved the final version before submission.

\section{Acknowledgements}

The first author (BD) is supported by the Special Research Fund (BOF) of Ghent University.

\section{Author details}

${ }^{1}$ Institute of Health and Society (IRSS), Faculty of Public Health, Université catholique de Louvain, Brussels, Belgium. ${ }^{2}$ Department of Virology, Parasitology and Immunology, Faculty of Veterinary Medicine, Ghent University, Salisburylaan 133, 9820 Merelbeke, Belgium. ${ }^{3}$ Department of Comparative Physiology and Biometrics, Faculty of Veterinary Medicine, Ghent University, Merelbeke, Belgium. ${ }^{4}$ Department of Biomedical Sciences, Institute of Tropical Medicine, Antwerp, Belgium. ${ }^{5}$ Division of Information, Evidence, Research, and Innovation, World Health Organization Regional Office for Europe, Copenhagen, Denmark. ${ }^{6}$ Department of Public Health and Surveillance, Scientific Institute of Public Health, Brussels, Belgium.

\section{Received: 6 May 2014 Accepted: 24 October 2014}

Published: 21 November 2014

\section{References}

1. Murray CJ, Ezzati M, Flaxman AD, Lim S, Lozano R, Michaud C, Naghavi M, Salomon JA, Shibuya K, Vos T, Wikler D, Lopez AD: GBD 2010: design, definitions, and metrics. Lancet 2012, 380:2063-2066.

2. Tan-Torres Edejer T, Baltussen R, Adam T, Hutubessy R, Acharya A, Evans D, Murray CJL: Making Choices in Health: WHO Guide to Cost-Effectiveness Analysis. Geneva: WHO Press; 2003.

3. Marshall SJ: Developing countries face double burden of disease. Bull World Health Organ 2004, 82:556.

4. Jelenc M, Van HE, Albreht T, Meglic M, Seljak M, Krnel SR: Joint action European partnership for action against cancer. Arch Public Health 2012, 70:24.

5. Bryant LL, Corbett KK, Kutner JS: In their own words: a model of healthy aging. Soc Sci Med 2001, 53:927-941.

6. Robine JM, Cambois E, Nusselder W, Jeune B, Oyen HV, Jagger C: The joint action on healthy life years (JA: EHLEIS). Arch Public Health 2013, 71:2.

7. Murray CJ, Salomon JA, Mathers C: A critical examination of summary measures of population health. Bull World Health Organ 2000, 78:981-994.

8. Murray C, Lopez A: The Global Burden of Disease: A Comprehensive Assessment of Mortality and Disability from Diseases, Injuries and Risk Factors in 1990 and Projected to 2020. Cambridge: Harvard University Press; 1996.

9. Lopez A, Mathers C, Ezzati M, Jamison D, Murray C: Global Burden of Disease and Risk Factors. New York: Oxford University Press; 2006.

10. World Health Organization: The Global Burden of Disease: 2004 Update. Geneva: WHO Press; 2008.

11. Murray CJ, Vos T, Lozano R, Naghavi M, Flaxman AD, Michaud C, Ezzati M, Shibuya K, Salomon JA, Abdalla S, Aboyans V, Abraham J, Ackerman I, Aggarwal R, Ahn SY, Ali MK, Alvarado M, Anderson HR, Anderson LM, Andrews KG, Atkinson C, Baddour LM, Bahalim AN, Barker-Collo S, Barrero LH, Bartels DH, Basáñez MG, Baxter A, Bell ML, Benjamin EJ, et al: Disability-adjusted life years (DALYs) for 291 diseases and injuries in 21 regions, 1990-2010: a systematic analysis for the global burden of disease study 2010. Lancet 2012, 380:2197-2223.
12. World Health Organization: WHO methods and data sources for global burden of disease estimates 2000-2011. [http://www.who.int/entity/ healthinfo/statistics/GlobalDALYmethods_2000_2011.pdf]

13. The World Bank: World Development Report 1993: Investing in Health. New York: Oxford University Press; 1993.

14. Murray CJ: Quantifying the burden of disease: the technical basis for disability-adjusted life years. Bull World Health Organ 1994, 72:429-445.

15. Murray CJ, Acharya AK: Understanding DALYs (disability-adjusted life years). J Health Econ 1997, 16:703-730.

16. Devleesschauwer B, Havelaar AH, Maertens de Noordhout C, Haagsma JA, Praet N, Dorny P, Duchateau L, Torgerson PR, Van Oyen H, Speybroeck N: Calculating disability-adjusted life years to quantify burden of disease. Int J Public Health 2014, 59:565-569.

17. Barendregt JJ, Bonneux L, Van der Maas PJ: DALYs: the age-weights on balance. Bull World Health Organ 1996, 74:439-443.

18. Arnesen T, Kapiriri L: Can the value choices in DALYs influence global priority-setting? Health Policy 2004, 70:137-149.

19. Devleesschauwer B, Havelaar AH, Maertens de Noordhout C, Haagsma JA, Praet N, Dorny P, Duchateau L, Torgerson PR, Van Oyen H, Speybroeck N: DALY calculation in practice: a stepwise approach. Int J Public Health 2014, 59:571-574.

20. Muyldermans G, Litzroth A, Ducoffre G, Quoilin S: Establishment and reinforcement of the national reference centers for human microbiology in Belgium. Arch Public Health 2012, 70:16.

21. Boffin N, Bossuyt N, Vanthomme K, Van Casteren V: Readiness of the Belgian network of sentinel general practitioners to deliver electronic health record data for surveillance purposes: results of survey study. BMC Fam Pract 2010, 11:50.

22. Commission for the protection of privacy, Royal Decree 2001, Belgium. [http://www.privacycommission.be/sites/privacycommission/files/documents/ Royal_Decree_2001.pdf]

23. Bilcke J, Van DP, De SF, Hanquet G, Van RM, Beutels P: The health and economic burden of rotavirus disease in Belgium. Eur J Pediatr 2008, 167:1409-1419.

24. D'Havé A: Aankondiging omschakeling van ICD-9-CM naar ICD-10-BE vanaf 1 januari 2015 (Announcement conversion of ICD-9-CM to ICD-10-BE from January 1, 2015). Brussels: FPS Health, Food chain safety and Environment; 2011.

25. Vanthomme $\mathrm{K}$, Walckiers $\mathrm{D}$, Van $\mathrm{OH}$ : Belgian health-related data in three international databases. Arch Public Health 2011, 69:6.

26. Kuchenmüller T, Hird S, Stein C, Kramarz P, Nanda A, Havelaar AH: Estimating the global burden of foodborne diseases-a collaborative effort. Euro Surveill 2009, 14:19195.

27. Institute for Health Metrics and Evaluation (IHME): Global Burden of Disease Study 2010. Belgium Global Burden of Disease Study 2010 (GBD 2010) Results 1990-2010. [http://ghdx.healthdata.org/record/ belgium-global-burden-disease-study-2010-gbd-2010-results-1990-2010]

28. Institute for Health Metrics and Evaluation (IHME): GBD Profile: Belgium. [http://www.healthdata.org/sites/default/files/files/country_profiles/GBD/ inme_gbd_country_report_belgium.pdf]

29. Institute for Health Metrics and Evaluation (IHME): The Global Burden of Disease: Generating Evidence, Guiding Policy - European Union and European Free Trade Association Regional Edition. Seattle, WA: Institute for Health Metrics and Evaluation; 2013.

30. Kretzschmar M, Mangen MJ, Pinheiro P, Jahn B, Fevre EM, Longhi S, Lai T, Havelaar AH, Stein C, Cassini A, Kramarz P, BCoDE consortium: New methodology for estimating the burden of infectious diseases in Europe. PLOS Med 2012, 9:e1001205.

31. van Lier EA, Havelaar AH: Disease burden of infectious diseases in Europe: a pilot study. [http://www.rivm.nl/bibliotheek/rapporten/215011001.pdf]

32. Baert E, Van Oyen H, Aelvoet W, De Henauw S, De Backer G: DALY (disability adjusted life years): een conceptueel model van geïntegreerde gezondheidsindicator op basis van verloren levensjaren door voortijdige sterfte en ziekte (DALY (disability adjusted life years): a conceptual model of integrated health indicator based on years of life lost due to premature death and disease). In Gezondheidsindicatoren 1998. Brussels: Flemish Agency for Care and Health; 2000.

33. Baert E, De Backer G, Byttebier G, De Henauw S, Van Oyen H, Aelvoet W: Disability Adjusted Life Years. Een eerste berekening voor Vlaanderen (Disability Adjusted Life Years. A first calculation for Flanders). In Gezondheidsindicatoren 2000. Brussels: Flemish Agency for Care and Health; 2002. 
34. Melse JM, Essink-Bot ML, Kramers PG, Hoeymans N: A national burden of disease calculation: Dutch disability-adjusted life-years. Am J Public Health 2000, 90:1241-1247.

35. Buekers J, Torfs R, Deutsch F, Lefebvre W, Bossuyt M: Inschatting ziektelast en externe kosten veroorzaakt door verschillende milieufactoren in Vlaanderen (Assessment of Disease Burden and External Costs Caused by Various Environmental Factors in Flanders). Mechelen: Flemish Environment Agency (VMM); 2012.

36. Stassen KR, Collier P, Torfs R: Environmental burden of disease due to transportation noise in Flanders (Belgium). Transport Res D Transport Environ 2008, 13:355-358.

37. Dhondt S, Macharis C, Terryn N, Van MF, Putman K: Health burden of road traffic accidents, an analysis of clinical data on disability and mortality exposure rates in Flanders and Brussels. Accid Anal Prev 2013, 50:659-666.

38. Henrard S, Devleesschauwer B, Beutels P, Callens M, De Smet F, Hermans C, Speybroeck N: The health and economic burden of haemophilia in Belgium: a rare, expensive and challenging disease. Orphanet J Rare Dis 2014, 9:39.

39. Ikram UZ, Kunst AE, Lamkaddem M, Stronks K: The disease burden across different ethnic groups in Amsterdam, the Netherlands, 2011-2030. Eur J Public Health 2014, 24:600-605.

40. Gilmour S, Liao Y, Bilano V, Shibuya K: Burden of disease in Japan: using national and subnational data to inform local health policy. J Prev Med Public Health 2014, 47:136-143.

41. Mathers CD, Vos ET, Stevenson CE, Begg SJ: The burden of disease and injury in Australia. Bull World Health Organ 2001, 79:1076-1084.

Cite this article as: Devleesschauwer et al:: Quantifying burden of disease to support public health policy in Belgium: opportunities and constraints. BMC Public Health 2014 14:1196.

\section{Submit your next manuscript to BioMed Central and take full advantage of:}

- Convenient online submission

- Thorough peer review

- No space constraints or color figure charges

- Immediate publication on acceptance

- Inclusion in PubMed, CAS, Scopus and Google Scholar

- Research which is freely available for redistribution 